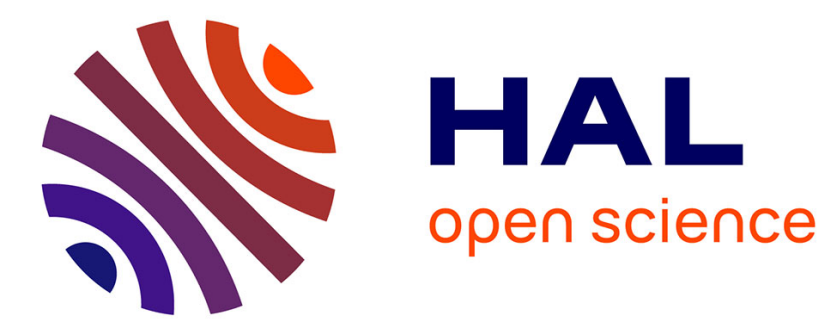

\title{
PLASTIC DEFORMATION OF SLIGHTLY REDUCED RUTILE
}

\author{
M. Vrinat, M. Blanchin
}

\section{To cite this version:}

M. Vrinat, M. Blanchin. PLASTIC DEFORMATION OF SLIGHTLY REDUCED RUTILE. Journal de Physique Colloques, 1981, 42 (C3), pp.C3-79-C3-94. 10.1051/jphyscol:1981309 . jpa-00220700

\section{HAL Id: jpa-00220700 https://hal.science/jpa-00220700}

Submitted on 1 Jan 1981

HAL is a multi-disciplinary open access archive for the deposit and dissemination of scientific research documents, whether they are published or not. The documents may come from teaching and research institutions in France or abroad, or from public or private research centers.
L'archive ouverte pluridisciplinaire HAL, est destinée au dépôt et à la diffusion de documents scientifiques de niveau recherche, publiés ou non, émanant des établissements d'enseignement et de recherche français ou étrangers, des laboratoires publics ou privés. 


\title{
PLASTIC DEFORMATION OF SLIGHTLY REDUCED RUTILE
}

\author{
M. Vrinat and M.G. Blanchin \\ Département de Physique des Matériaus (*), Université claude Bemard Lyon I \\ 43, boulevard du 11 Novembre 1918, 69622 Vilieurbanne Cedex, France
}

\begin{abstract}
Résumé.- Des monocristaux de rutile ont étê rêduits à la température de $\overline{1323 \bar{K}}$ sous faible pression partielle d'oxygène à différentes compositions dans 1 'intervalle $\mathrm{TiO}_{2}, 0000^{-} \mathrm{T}^{\prime} \mathrm{O}_{1,9965}$ puis déformés plastiquement en compression uniaxiale à la méme température, tout en maintenant la composition. La variation de la limite élastique en fonction de l'écart à la stoechiométrie montre qu'il existe deux régimes dans le comportement mécanique de $\mathrm{TiO}_{2-x}$ en fonction de la valeur de $\mathrm{x}$. Dans le premier régime c'est à dire pour de faibles degrés de réduction ( $0 / \mathrm{Ti}>1,9985)$, la limite élastique diminue quand l'écart à la stoechiométrie augmente. Pour des degrés de réduction plus important $(\mathrm{O} / \mathrm{Ti} \leq 1,9985)$, on observe un fort effet de durcissement : la limite élastique augmente quand l'écart à la stoechiométrie augmente.

Des mesures du volume d'activation dans ces deux régimes suggèrent que le comportement mécanique du rutile réduit à $1323 \mathrm{~K}$ peut être analysé en termes d'interaction entre dislocations et défauts ponctuels : défauts ponctuels intrinsèques (titane interstitiel) aux forts degrés de réduction et impuretés extrinsèques pour des compositions se rapprochant de $\mathrm{TiO}_{2}$.
\end{abstract}

\begin{abstract}
Rutile single crystals were reduced at the temperature of $1323 \mathrm{~K}$ under low oxygen pressure to different compositions in the range $\mathrm{TiO}_{2.0000-}$ TiO 1,9965 and plastically deformed under uniaxial compression at the same temperature while maintaining the composition. The dependence of the flow stress on the departure from stoichiometry suggests that two regimes of mechanical behavior exist for $\mathrm{TiO}_{2-x}$ depending on the value of $x$. In the first regime, i.e. for slight degrees of reduction ( $\mathrm{O} / \mathrm{Ti}>1.9985)$, the flow stress decreases when $0 / \mathrm{T} i$ decreases. For larger degrees of reduction ( $0 / \mathrm{Ti} \leq 1.9985$ ) a marked hardening effect is observed and the flow stress increases as the departure from stoichiometry increases. Measurements of the activation volume in these two regimes suggest that the plastic behavior of rutile reduced at $1323 \mathrm{~K}$ could be explained in terms of interaction between dislocations and point defects, i.e. intrinsic point defects (titanium interstitials) at the largest departures from stoichiometry and extrinsic impurities for compositions close to $\mathrm{TiO}_{2}$.
\end{abstract}

Introduction.- Rutile is the stable form of $\mathrm{TiO}_{2}$, the highest oxide of the ri - O system. The crystal structure of the oxides in the composition range $\mathrm{Ti}_{3} \mathrm{O}_{5}-\mathrm{TiO}_{2}$ has been extensively studied in the past to identify the defects accomodating non-stoichiometry of rutile.

It has been shown that the structure of the Magneli phases which correspond to the generic formula $\mathrm{Ti}_{\mathrm{n}} \mathrm{O}_{2 \mathrm{n}-1}$ with $4 \leq \mathrm{n} \leq 36$, can be described in terms of the periodic alignment of "crystallographic shear" planes (CSP) whose orientation is well defined but varies from $\{011\}$

(*) Associê au C.N.R.S. (LA 172) 
to $\{132\}$ and then to $\{121\}$ depending on the value of $\mathrm{n}$ (see Blanchin et al. $/ 1 /$ in this issue). On the other hand, the nature of defects in slightly reduced rutile may be still regarded as a matter of debate and this is discussed further by Blanchin et al. $/ 1 /$ in the present issue.

Physical properties of $\mathrm{TiO}_{2-\mathrm{x}}$ oxides in the composition range $\mathrm{TiO}_{1.960}-\mathrm{TiO}_{2.000}$ have been studied as a function of the departure $x$ from stoichiometry under equilibrium conditions, i.e. controlled partial pressure of oxygen at elevated temperatures $1000-1800 \mathrm{~K}$. The results of thermogravimetric $/ 2 /$, electromotive force $/ 3,4 /$ and electrical conductivity /5/ measurements show three distinct regions of behavior. The first region corresponds to the highest temperatures and the lowest values of $x$; it has been interpreted (see for instance reference $/ 5 /)$, as due to the existence of a homogeneous solid solution $\mathrm{TiO}_{2-\mathrm{x}}$ of isolated point defects in the perfect rutile matrix and it was argued that the point defects are titanium interstitials, rather than oxygen vacancies /5/. At lowest temperatures and largest values of $x$, ordered structure phases $\mathrm{Ti}_{n} \mathrm{O}_{2 n-1}$ represent the minimum free energy whereas the intermediate region is regarded as a diphasic one, corresponding to the existence of binary compounds $\mathrm{Ti}_{n} \mathrm{O}_{2 \mathrm{n}-1}-\mathrm{TiO}_{2-\mathrm{x}}$. Results of studies $/ 2 /$ to $/ 5 /$ allow to determine analytical equations involving the departure $x$, the temperature and the oxygen pressure. From these data we have calculated the solvus curves separating the three regions described above. The curves are plotted in figure 1 , in terms of 0 to $T i$ ratio versus temperature, defining a possible solid phase diagram.

The defect structure of slightly reduced rutile $\mathrm{TiO}_{2-\mathrm{x}}$ with $\mathrm{x} \leq$ 0.003 was studied by Blanchin et al. $/ 6 /$ by means of transmission electron microscopy (TEM). CSP were not observed in crystals quenched from the reduction temperature of $1323 \mathrm{~K}$ but appeared only if the quenched crystals had been mechanically deformed before the reduction process. The aim of the present work was therefore to study the interaction between dislocations and non-stoichiometric defects in reduced and deformed rutile.For this purpose, rutile single crystals were reduced at high temperature under low oxygen pressure to different compositions in the range $\mathrm{TiO}_{1.9965}-\mathrm{TiO}_{2.0000}$ and then plastically deformed under uniaxial compression at the same temperature while maintaining the composition. The partial pressure of oxygen was controlled using $\mathrm{CO}-\mathrm{CO}_{2}$ gas mixtures. The critical resolved shear stress and the activation volume for the active slip system were measured as a function of the departure from stoichiometry in correlation with T.E.M. observations of the microstructure. 


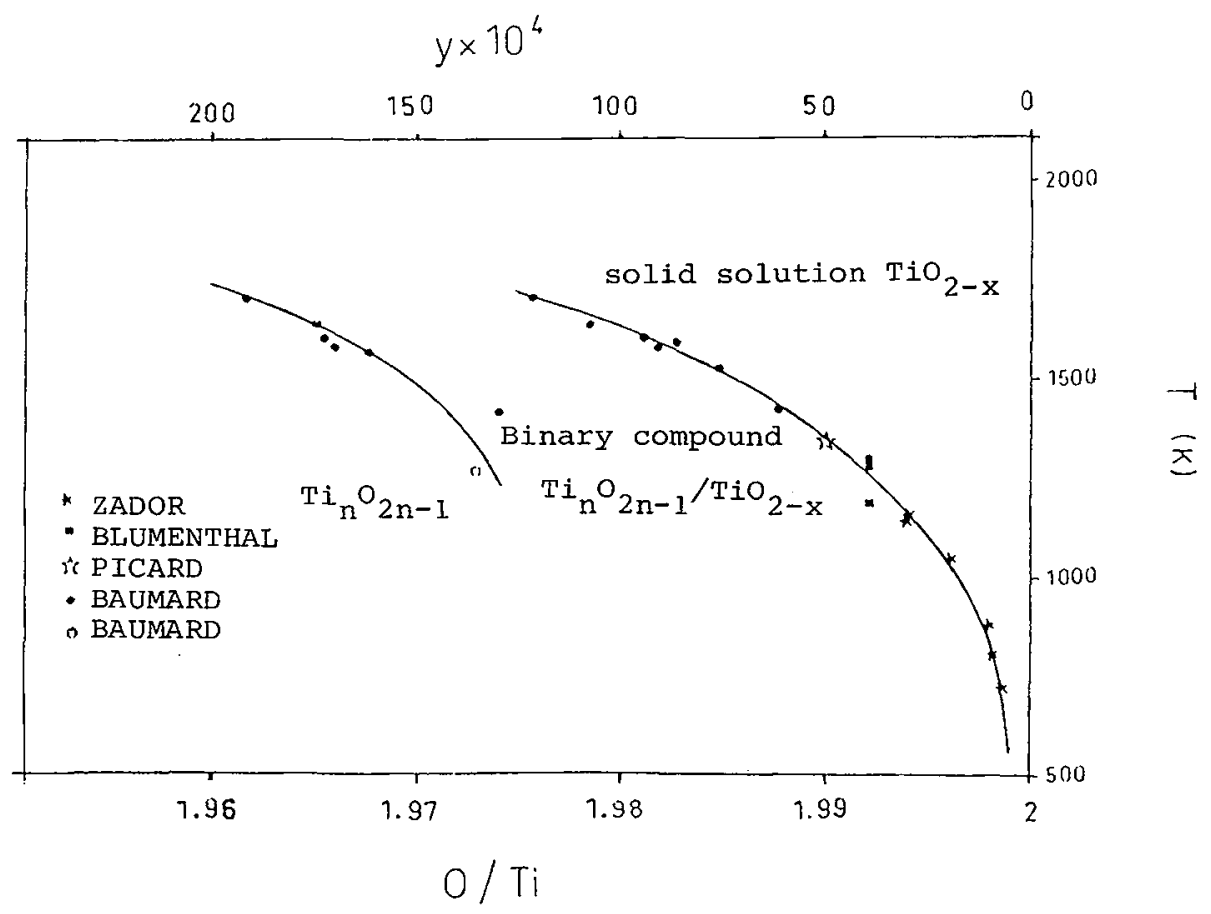

Fig. 1.- Phase diagram for the Ti-0 system near TiO 2 . Data calculated from the results of $x$ Zador $/ 4 /$, Blumenthal and Whitmore $/ 3 / 2$, Picard and Gerdanian $/ 2 /$, - Baumard /5/, a Baumard (thermogravimetric measurements).

2. Experimental.- Single crystal boules of undoped rutile grown by the Verneuil flame fusion method were purchased from Djevahirdjian Co. These boules had been annealed after growth at $1973 \mathrm{~K}$ in oxygen for several hours and then slowly cooled to room temperature : this insured that the crystals were stoichiometric /6/. Spectrographic analysis of the boules revealed a total impurity content of about $500 \mathrm{ppm}$, the main impurity being aluminum. Specimens were cut from the boules $/ 6 /$ as parallelepipeds $\left(2.8 \times 2.8 \times 6 \mathrm{~mm}^{3}\right)$ oriented so that the [001] axis was parallel to the largest dimension.

Reduction and deformation of the crystals under uniaxial compression parallel to [001] axis were performed in a standard Instron machine equipped with a furnace allowing temperature up to $1350 \mathrm{~K}$. The needed oxygen partial pressures $\mathrm{pO}_{2}$ were obtained by using the high temperature equilibrium properties of $\mathrm{CO}-\mathrm{CO}_{2}$ gas mixtures dissolved in $\mathrm{N}_{2}$. The gases were purified by flowing through a copper column at $650 \mathrm{~K}$ and then mixed in the choosen proportions by means of wosthoff mixing pumps maintaining a flow rate of $25 \mathrm{l} / \mathrm{h}$. The final gas mixture flowed past the crystal in an air tight silica tube. Technical aspects of the 
apparatus and further details of the experimental procedure have been reported by vrinat $/ 7 /$.

Standard calculations /2/ allowed to determine the value of $\mathrm{pO}_{2}$ corresponding a choosen value of the $\mathrm{O} / \mathrm{T} i$ ratio. Due to the incertitude on the value of the temperature $\left( \pm 5 \mathrm{~K}\right.$ ) and pressure ratio $\mathrm{pCo} / \mathrm{pCO}_{2}$ $\left( \pm 4 \times 10^{-3}\right)$, the $\mathrm{O} / \mathrm{Ti}$ ratio was finally determined with an incertitude of $\pm 3 \times 10^{-5}$. This was checked by means of thermogravimetric measurements during reoxidation of some of the reduced crystals to the stoichiometric composition.

The crystals were annealed 24 hours at $1323 \mathrm{~K}$ before the deformation test, in order to insure thermodynamic equilibrium of the defects. At the end of the compression test, the samples were cooled in a dynamical vacuum of $10^{-6}$ torr. This was shown to preserve the composition of the crystals $/ 6 /$.

Thin foils of different crystallographic orientations were prepared from the bulk specimens following the procedure described by Blanchin et al. /6/. They were examined in a Philips EM 300 microscope at $100 \mathrm{kV}$.

3. Results.- 3.1. Mechanical behavior.- Regarding to the results of previous studies $/ 6 /$, the present crystals were reduced at the temperature of $1323 \mathrm{~K}$ to compositions ranging from $\mathrm{TiO}_{2.0000}$ to $\mathrm{TiO}_{1.9965}\left(10^{-15}\right.$ atm. $<\mathrm{pO}_{2}<1$ atm.) All the compression tests were conducted at the temperature of reduction and at a strain rate of $5.65 \times 10^{-5} \mathrm{~s}^{-1} / 8 /$. Due to the compression of the specimens along the [001] axis, the equivalent $\{101\}\langle\bar{I} 01\rangle$ slip systems were activated $/ 8 /$.

3.1.1. Stress-strain curves.- Depending on the value of the o/Ti ratio, four characteristic types of stress-strain curves were recorded which are reproduced in figure 2 (plotted in rational coordinates). All the curves exhibited an elastic region followed by a plastic region with an initial linear part.

Curve (a) corresponds to the stoichiometric composition $\mathrm{TiO}_{2}$. Several tests led to determine a mean value of the flow stress which was about $6.5 \mathrm{daN} / \mathrm{mm}^{2}$, in agreement with results of previous investigations $/ 8,9 /$. A distinctive feature of the curves were marked steps just after yielding, which involved $\delta \sigma$ of $\sim 0.01-0.03 \mathrm{daN} / \mathrm{mm}^{2}$ and $\delta \varepsilon$ of $\sim 10^{-4}$ (so that these steps could not be reproduced at the scale of figure 2). This serrated flow was shown to be due to a dynamic strain ageing (DSA) effect $/ 9 /$.

For departures from stoichiometry corresponding to $2<0 / \mathrm{T} i<1.9980$, the values of the flow stress and of the work-hardening rate just after yielding were found to be smaller than for $\mathrm{TiO}_{2}$ (Fig. 2b). Again serrated flow was observed after yielding. 


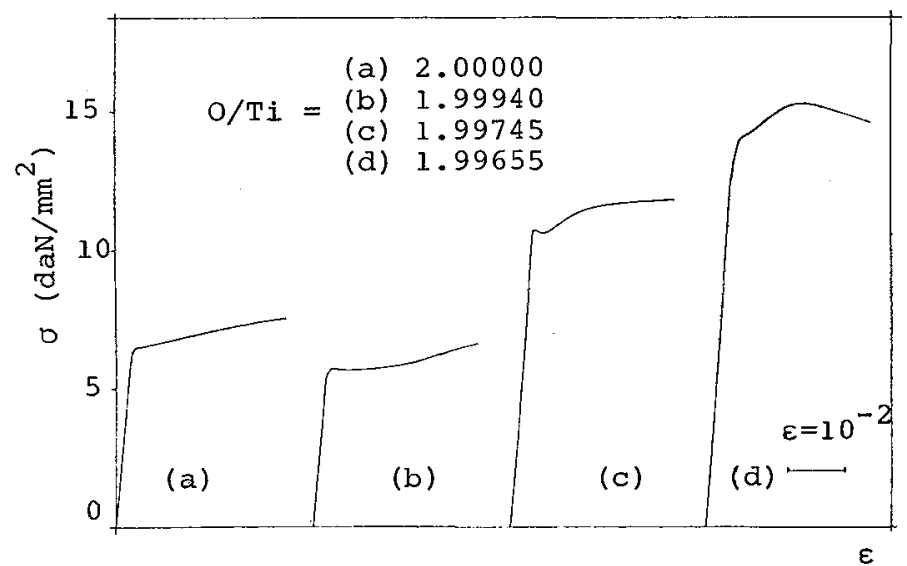

Fig. 2.- Influence of the departure from stoichiometry on the form of the stressstrain curves.

For $1.9930 \leq 0 / \mathrm{Ti}<1.9970$ (Fig. 2c) a yield drop of relatively small amplitude was often observed and the flow stress was found to increase markedly. The work-hardening rate appeared to be larger than in $\mathrm{TiO}_{2}$ immediatly after yielding, but was found to decrease and tend to zero for values of strain $\varepsilon$ exceeding $2 \times 10^{-2}$.

For $1.9970 \leq \mathrm{O} / \mathrm{Ti}<1.9960$ (Fig. 2d), the flow stress continued to increase (up to three times the value in $\mathrm{TiO}_{2}$ ) but the yield drop and the serrated flow were not observed anymore. The work-hardening rate was large immediately after yielding but became null and even negative (work-softening) for strain values $\varepsilon>2 \times 10^{-2}$. Such a work-softening effect had never been observed during plastic deformation of stoichiometric $\mathrm{TiO}_{2}$ even at higher temperatures and larger strains /8,9/. 3.1.2. Dependence of the flow stress and of the work-hardening rate on the departure from stoichiometry.-

a) Variation of the flow stress.- In figure 3 is plotted the variation of the flow stress taken as the stress $\sigma_{e}$ at the beginning of the linear work-hardening region /9/ as a function of the composition expressed in terms of $\mathrm{O} / \mathrm{Ti}$ ratio (a quite similar variation could be observed on the plot of the yield. stress taken at the departure of the stress-strain curve from the elastic slope /7/).

Two regions can be delineated in figure 3. For compositions corresponding to $\mathrm{O} / \mathrm{T} i \geq 1.9985$, the flow stress decreases at increasing departure from stoichiometry. In the second region i.e. O/Ti< 1.9985 , the flow stress increases as the degree of reduction increases.

b) Variation of the work-hardening rate.- No influence of the departure from stoichiometry on the slope of the stress-strain curves 


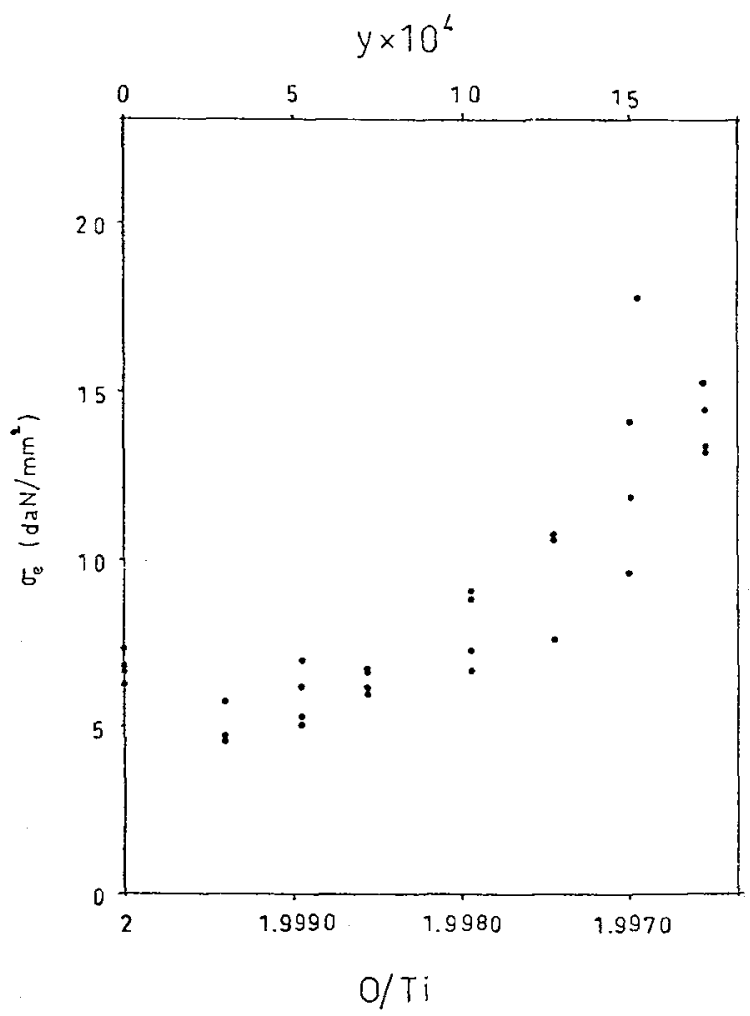

Fig. 3.- Flow stress versus $0 / \mathrm{Ti}$ ratio (the different sets of measurements for each composition were done on specimens randomly cut from the same boule).

could be detected in the elastic region of the curves. On the other hand the work-hardening rate after yielding, taken as the slope of the initial linear part of the plastic region, did exhibit a significant hardening effect for values of $\mathrm{O} / \mathrm{Ti}<1.9980$ (Fig. 2): the work-hardening rate in this region was found to be about $1.8 \times 10^{2} \mathrm{daN} / \mathrm{mm}^{2} \mathrm{com}-$ pared to a mean value of $0.6 \times 10^{2} \mathrm{daN} / \mathrm{mm}^{2}$ for compositions ranging from $\mathrm{TiO}_{2.000}$ to $\mathrm{TiO}_{1.998^{\circ}}$

c) Regimes of behavior.- All the results so far presented support the idea that two regimes of mechanical behavior exist for $\mathrm{TiO}_{2-x^{\prime}}$ depending on the departure from stoichiometry. In the first regime, i.e. for slight degrees of reduction, the flow stress shows a slight decrease but the other mechanical features appear rather similar to those of $\mathrm{TiO}_{2}$. For larger degrees of reduction, the serrated flow effect disappears and a marked hardening effect is observed involving both the flow stress and the work-hardening rate after yielding whereas worksoftening is observed at large strains. 
Fig. $4 \mathrm{a}$

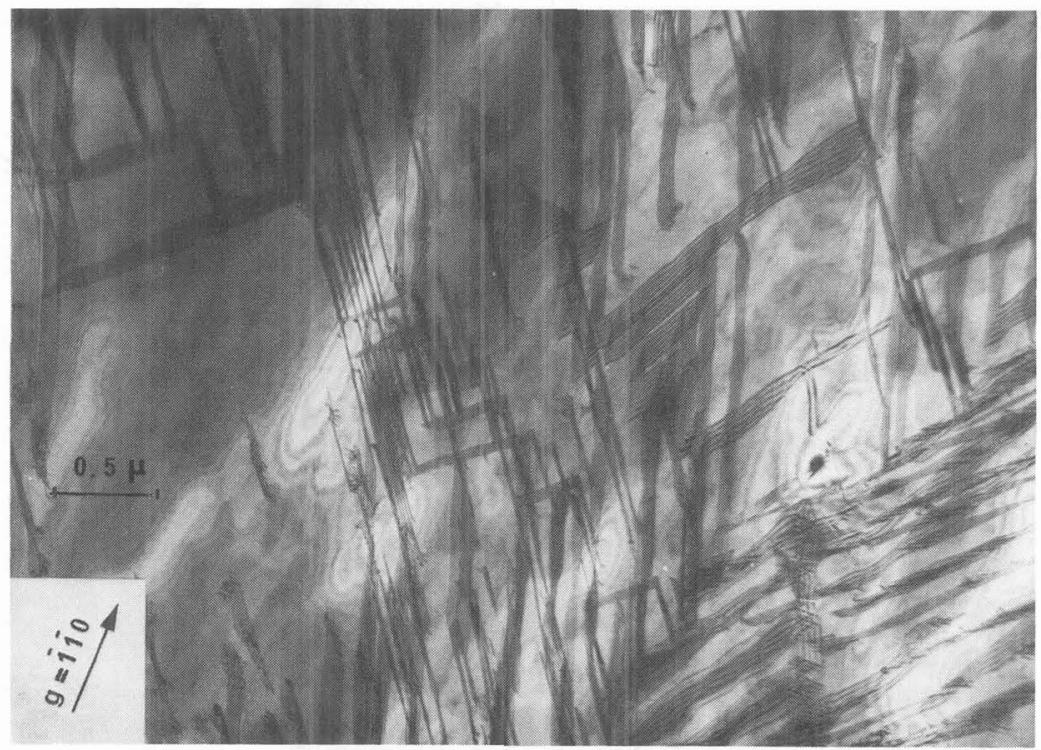

Fig. $4 \mathrm{~b}$

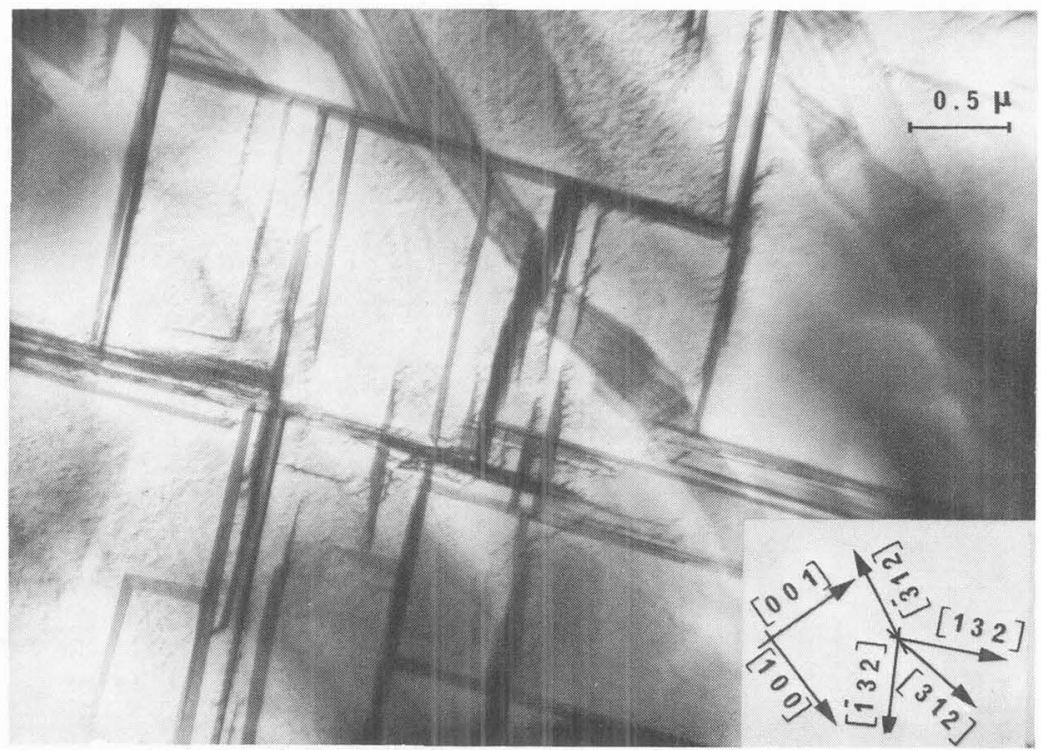

Fig. 4.- Microstructure of non-stoichiometric rutile at increasing degree of reduction as shown by bright-field (BF) electron micrographs $g^{f}$ foils cut from samples

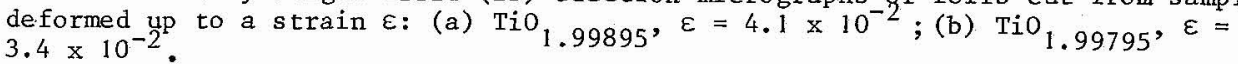


Fig. 5 a

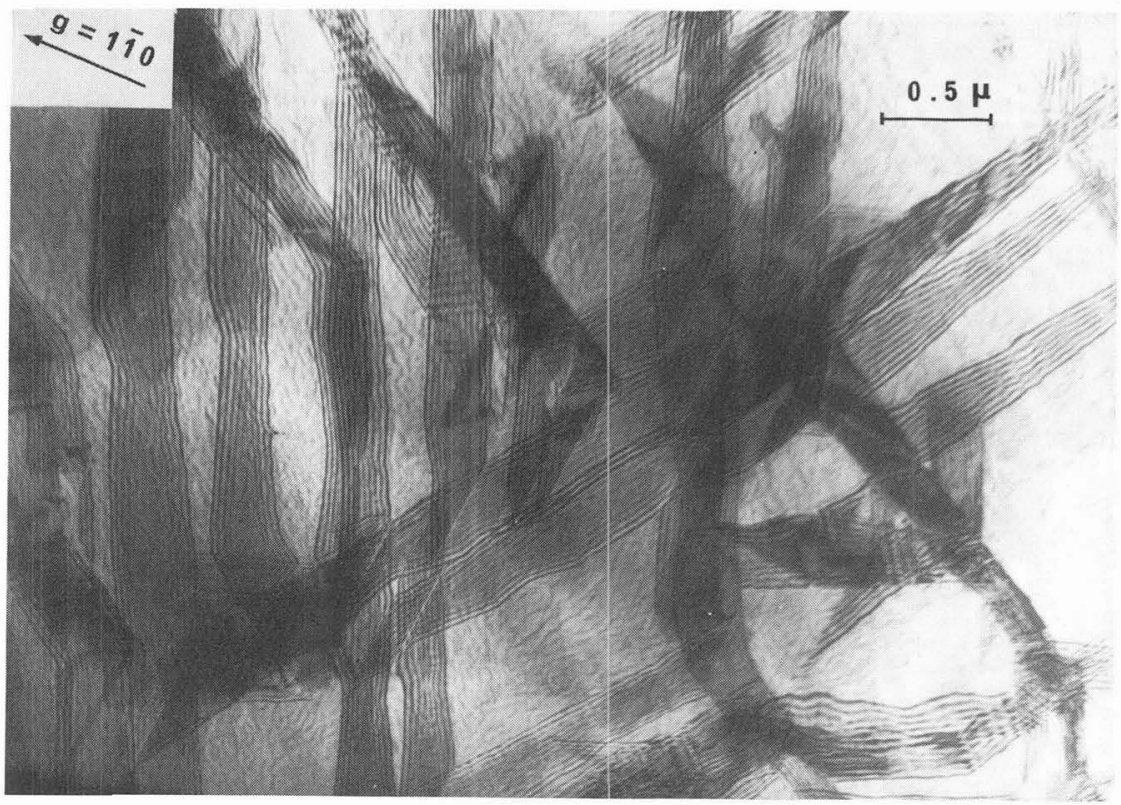

Fig. $5 \mathrm{~b}$
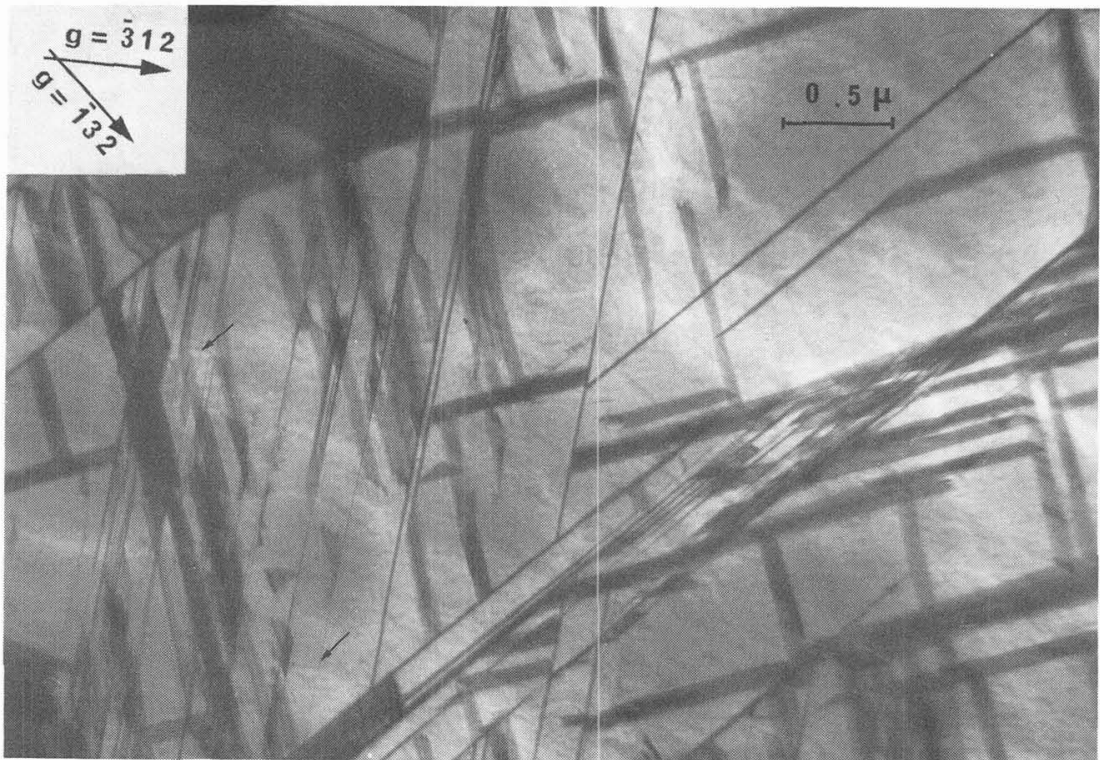

Fig. 5.- BF micrographs of foils cut from Tio 1.99655 crystals deformed at increasing strains: (a) $\varepsilon=0.84 \times 10^{-2}$; (b) $\varepsilon=3.8 \times 10^{-2}$. Faults viewed edge on are arrowed. 
3.2. Transmission_electron_microscope_studies_- Microstructure of the TiO $_{2-x}$ crystals after deformation was thus studied by means of TEM observations regarding to the different aspects of the mechanical behavior.

In figure 4 are shown micrographs taken from crystals deformed up to about the same strain but for increasing degrees of reduction whereas figure 5 shows the microstructure of $\mathrm{TiO}_{1.99655}$ crystals at increasing strains. All the microstructures were found to be very similar. No isolated dislocation was seen but a roughly constant density of fringe contrasts was observed and contrast experiments showed that these fringes were characteristic of extended planar defects. The traces of the planes of the faults when intersecting a $\{010\}$ plane were found close to equivalent <132> directions (Fig. 4b) and some faults could be put edge on perpendicular to 132 diffraction vectors when imaging foils with the electronbeam parallel to a $\langle\bar{l} \overline{2}\rangle$ zone axis (Fig. $5 \mathrm{~b}$ ). It was thus concluded that the mean orientation of the fault planes was close to $\{132\}$, which is indeed a CSP orientation. (One did not observe any evidence for fault planes close to $\{121\}$ orientations). Higher resolution TEM observations and further discussion of the orientation of the CS defects present in the crystals are reported later in this issue $/ 1 /$.

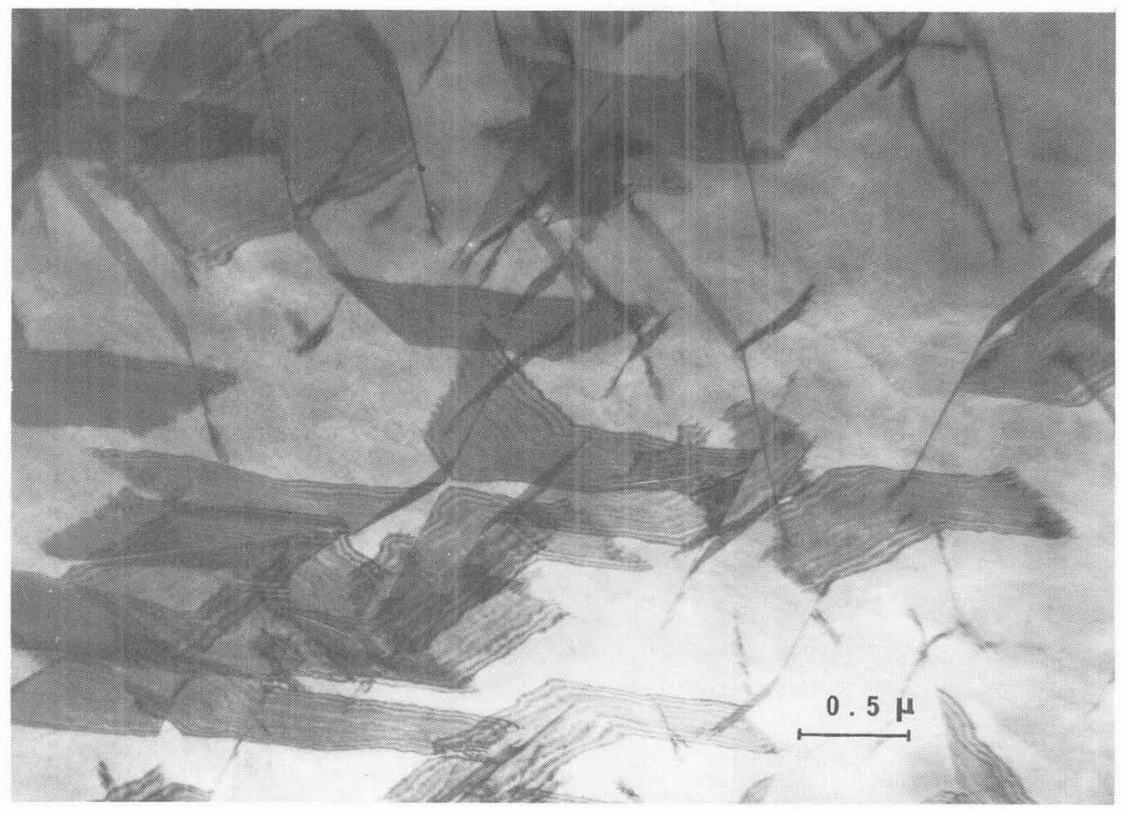

Fig. 6.- CS planes revealed by a BF micrograph of a foil from a non-deformed Tio 1.99855 crystal. 
Micrographs of figures 4 and 5 suggest that neither the composition, regarding to the two regimes of mechanical behavior previously discussed, nor the value of the strain regarding to the shape of the stress-strain curves (compare, for instance, figures $5 \mathrm{a}$ and $\mathrm{b}$ with figure 2d) do not seem to have any significant influence on the microstructure observed at room temperature.

Therefore non-deformed crystals reduced and cooled in the deformation apparatus following the same experimental procedure were also studied 5y TEM and CS planes of mean orientation close to $\{132\}$ were also observed in many areas of such non-deformed specimens, as shown in figure 6 .

Blanchin et al. /6/ did not observe any CSP in non-deformed rutile crystals reduced up to $\mathrm{TiO}_{1.9965}$ at $1323 \mathrm{~K}$ and then quenched from this temperature. Such a result was regarded as consistent with the diagram drawn in figure 1. Compared to the quench rate obtained by Blanchin et al. /6/, the cooling rate in the present case (Fig. 7) appears slower, especially for temperatures below $1000 \mathrm{k}$. A demixtion in two phases corresponding to the diphasic region of the diagram (Fig. 1), could thus occur during cooling.

All these results taken together suggest that the microstructures observed at room temperature in the present case might be not representative of the structure of the crystals at the temperature of reduction

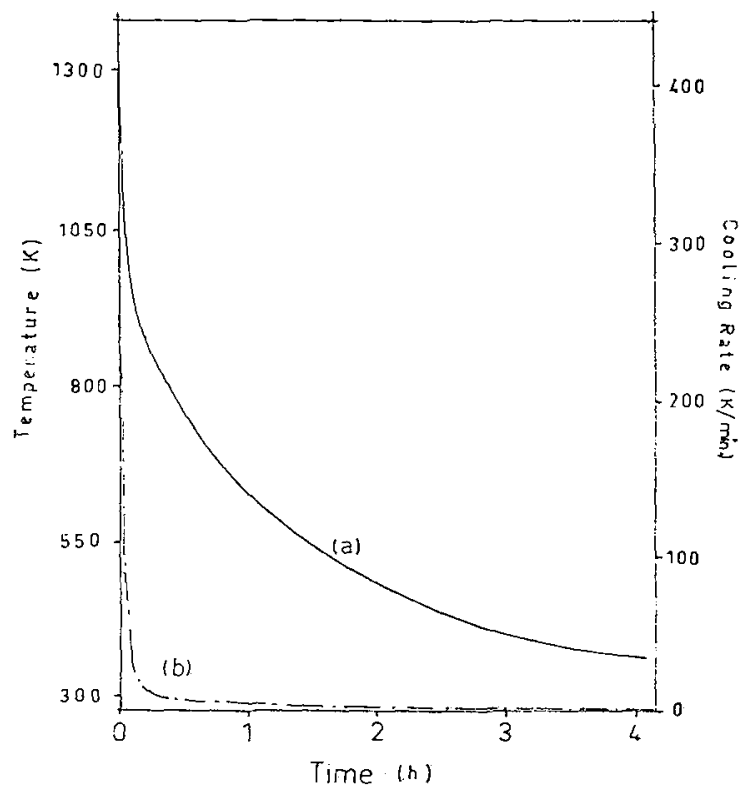

Fig. 7.- Cooling procedure : temperature (a) and cooling rate (b) versus time. 
and deformation as far as the observed CSP could have been nucleated from the dislocations (produced by the deformation) during the cooling of the samples $/ 6 /$.

4. Discussion.- In order to identify the deformation mechanisms operating in reduced rutile at $1323 \mathrm{~K}$, further investigations of the mechanical behavior were made, especially through measurements of the activation volume.

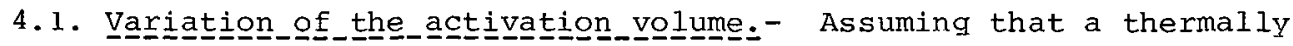
activated deformation mechanism may operate in the present case, apparent activation volumes were measured at $1323 \mathrm{k}$ using stress-relaxation experiments at small plastic strains. The ratio of the activation volume $v_{a}$ to $b^{3}$, with $\vec{b}=\langle\bar{l} 01\rangle$ being the Burgers vector of the glissile dislocations in the activated slip systems $/ 9 /$, is plotted against the composition in figure 8 . Again two regions can be clearly distinguished in this plot, which correlate well with the two regimes of behavior previously described in $\$ 3.1 .2$.

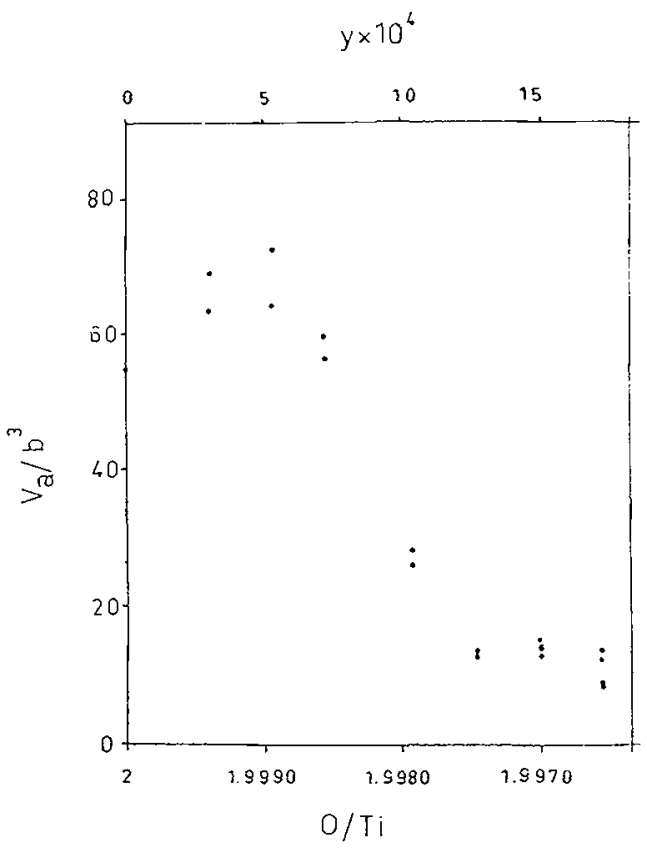

Fig. 8.- Ratio of the activation volume to $\mathrm{b}^{3}(\mathrm{~b}=5.46 \AA$ ) versus $0 / \mathrm{Ti}$ ratio. Two measurements were done on each specimen at very near values of the strain. For some compositions, measurements were repeated on two different specimens.

For the lowest degrees of reduction, i.e. O/Ti $\geq 1.9985$, the values of the activation volume are close to that measured in $\mathrm{TiO}_{2}$, the order of magnitude being $60 \mathrm{~b}^{3}$.

For ratios $\mathrm{O} / \mathrm{T} \boldsymbol{i}<1.9985$, the activation volume decreases at increasing departure from stoichiometry and this decrease is obviously 
correlated with the increase in the flow stress and in the work-hardening rate observed in the same range of composition. The corresponding order of magnitude of the activation volume $\left(v_{a}<40 b^{3}\right)$ may be regarded as possibly significant of a point defect - dislocation interaction (see for instance /10/). Such a conclusion seems to be consistent with the phase diagram presented in figure 1 , where it can be seen that the expected equilibrium phase at $1323 \mathrm{~K}$ for $\mathrm{O} / \mathrm{Ti} \geq 1.9960$ is the solid solution of titanium interstitials in the rutile matrix. The yielding mechanism in reduced rutile could thus be governed by the interaction between the glissile dislocations and the titanium interstitials ("intrinsic" regime), since for $\mathrm{O} / \mathrm{Ti}<1.9985$ the atomic concentration of titanium interstitials exceeds $750 \mathrm{p} . \mathrm{p} . \mathrm{m}$. compared to the vasue of about 500 p.p.m. for the total concentration of cation impurities.

The concentration of point defects corresponding to a given value of the activation volume may be readily estimated since it is well known /10/ that

$$
\mathrm{v}_{\mathrm{a}}=\mathrm{b} \& \mathrm{x}
$$

where $\ell$ is the mean distance of the obstacles, i.e. the point defects, in the glide plane of the dislocations, and $x$ is the width of the obstacles.

Assuming that the dislocations only interact with point defects located in their slip plane, it follows that

$$
\ell^{2} \times n_{i}=i
$$

where $\mathrm{n}_{i}$ is the concentration (per unit of volume) of the point defects, i.e. here the titanium interstitials. Regarding to the composition range investigated, the order of magnitude of $n_{i}$ is small in the present case, so that the titanium interstitials can be assumed to remain isolated in the rutile matrix and then /10/

$$
\mathrm{x} \simeq \mathrm{b},
$$

from where it follows that

$$
\mathrm{n}_{i}=\mathrm{b}^{3} / \mathrm{v}_{\mathrm{a}}^{2}
$$


To $\mathrm{n}_{i}$ corresponds an atomic concentration of titanium interstitials

$$
y=n_{i} v_{c} / 2 \text {, }
$$

with $v_{c}$ being the volume of the unit cell, and the corresponding degree of reduction can be expressed in terms of $\mathrm{O} / \mathrm{Ti}$ ratio

$$
0 / T i=2-n_{i} V_{C}
$$

For each value of $\mathrm{V}_{\mathrm{a}}$ measured in the intrinsic regime, we have thus calculated the expected value of $\mathrm{O} / \mathrm{T} i$, a lower limit of the incertitude on this value being estimated from several measurements of $v_{a}$ at the same composition. Comparison of the calculated values of $\mathrm{O} / \mathrm{Ti}$ with the nominal (experimental) values (Table I) shows that the agreement between the two sets is rather good.

Table I.- Nominal and calculated values of the $0 / \mathrm{Ti}$ ratio regarding to the activation volume. Nominal values of $0 / \mathrm{Ti}$ are known within an incertitude $\pm 3 \times 10^{-5}$.

\begin{tabular}{|c|c|c|c|}
\hline $\begin{array}{c}\text { Nominal } \\
\text { o/Ti ratio }\end{array}$ & $\mathrm{v}_{\mathrm{a}} / \mathrm{b}^{3}$ & $\mathrm{n}_{\mathrm{i}}\left(\mathrm{m}^{-3}\right)$ & $\begin{array}{c}\text { Calculated } \\
\text { O/Ti ratio }\end{array}$ \\
\hline 1.99795 & $27 \pm 2$ & $(8.7 \pm 1.5) .10^{24}$ & \pm 0.0001 \\
\hline 1.99745 & $13 \pm 2$ & $(39 \pm 12) .10^{24}$ & $1.9976 \pm 0.0008$ \\
\hline 1.99700 & $14 \pm 2$ & $(33 \pm 9) .10^{-24}$ & $1.9979 \pm 0.0006$ \\
\hline 1.99655 & $11 \pm 2$ & $(56 \pm 20) .10^{24}$ & $1.9965 \pm 0.0012$ \\
\hline
\end{tabular}

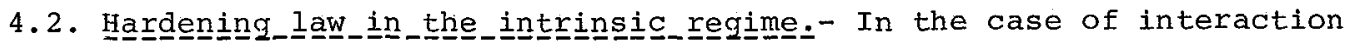
between dislocations and interstitial point defects in numerous metals and metallic alloys, the following hardening law has been reported/11/

$$
\sigma^{*} \propto c^{m}
$$

where $c$ is the atomic concentration of point defects and :

$$
\sigma^{*}=\sigma_{e}(c)-\sigma_{e}
$$

$\sigma_{e}(0)$ being the flow stress in the perfectly pure material. Blanchin et al. /9/ showed the influence of the impurities on the flow stress of stoichiometric $\mathrm{TiO}_{2} ;$ from those data, $\sigma_{e}(0)$ for 
pure $\mathrm{TiO}_{2}$ could be estimated equal to about $4 \mathrm{daN} / \mathrm{mm}^{2}$, what allows to calculate $\sigma^{*}(\mathrm{y})$ for $\mathrm{TiO}_{2-\mathrm{x}}$ in the intrinsic regime. In figure 9, we have plotted $\log \sigma^{*}(y)$ against $\log y$. Regarding to equation ( 1 ), the value of $\mathrm{m}$ which was computed from the plot by linear regression is $\mathrm{m}=1.8$. This value is higher than those commonly observed in metals where $0.5 \leq m \leq 1 / 11 /$. Such a result may be regarded as not surprising because of the iono-covalent character of the bonding in $\mathrm{TiO}_{2}$.

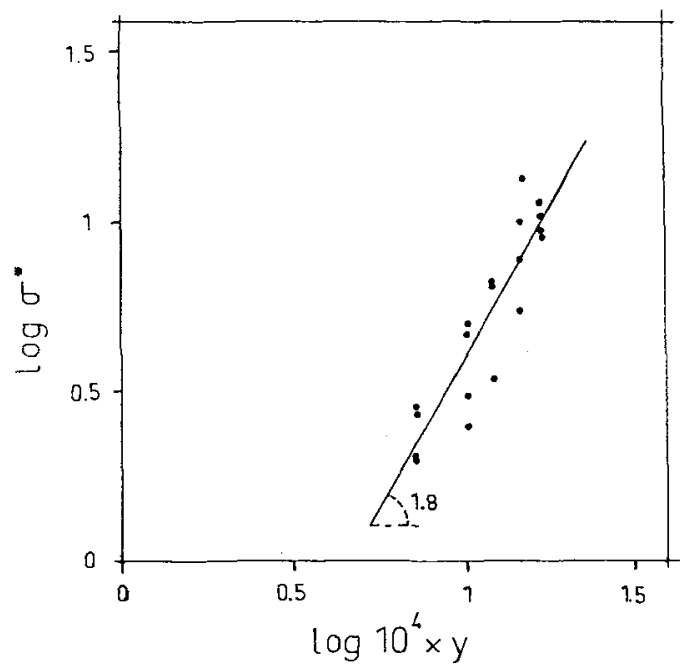

Fig.9. - $\log \sigma^{*}$ versus $\log \mathrm{y}$.

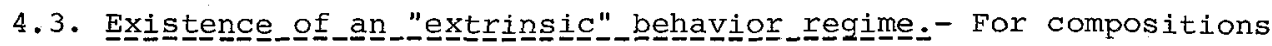
corresponding to $\mathrm{O} / \mathrm{Ti}>1.9985$, the plastic behavior of $\mathrm{TiO}_{2-\mathrm{x}}$ is very similar to that of $\mathrm{TiO}_{2}$, as reported above, in that the persistence of the serrated flow effect is observed.

Serrated flow occurring at $1323 \mathrm{~K}$ (for $\dot{\varepsilon}=5.65 \times 10^{-5} \mathrm{~s}^{-1}$ ) in stoichiometric rutile was interpreted by Blanchin et al. /9/ as significant of a DSA effect probably due to the main aliovalent impurities (especially Al) whose mobility is near the average mobility of the glissile dislocations.

For $\mathrm{O} / \mathrm{Ti} \geq 1.999$, the atomic concentration of the non-stoichiometric defects, i.e. the titanium interstitials, becomes of the same order as the total concentration of cation impurities detected in the present crystals, so that one may think that the yielding behavior of slightly reduced rutile would be more and more controlled by the impurities ("extrinsic regime") as the composition tends to $\mathrm{TiO}_{2}$. The transition from an intrinsic to an extrinsic behavior has been extensively reported by Baumard et al. $/ 12,13 /$. Electrical conductivity and thermoelectronic power of reduced rutile were found to decrease at decreasing 
departures from stoichiometry until they reach a minimum after which they increase as the composition tends to $\mathrm{TiO}_{2}$. This increase was interpreted as due to the impurities present in the crystals (?) and the minimum occurred for $\mathrm{O} / \mathrm{Ti} \simeq 1.99995$ at $1323 \mathrm{~K}$.

The energy of interaction between the dislocations and the impurities giving rise to DSA in stoichiometric $\mathrm{TiO}_{2}$ was found to be of short-range with the main contribution arising from electrostatic effects. Due to DSA, the flow stress of commercially available crystals of $\mathrm{TiO}_{2}$ is far higher than that expected for pure $\mathrm{TiO}_{2} / 9 /$. But the dissolution of aliovalent impurities in $\mathrm{TiO}_{2}$ leads to the formation of charge-compensating defects involving intrinsic point defects / $/$ so that the charge of the defects interacting with dislocations is expected to change as the concentration of intrinsic point defects increases. This could explain the progressive disappearance of DSA and hence the decrease in the flow stress observed at increasing departure from stoichiometry in the extrinsic regime. Since the mobility of the intrinsic point defects is different from that of the "active" impurities /9/, DSA is expected to disappear completely in the intrinsic regime.

5. Conclusion.- The results of the present work suggest that the mechanical behavior of rutile reduced up to the composition TiO 1.9965 at $1323 \mathrm{~K}$ could be explained in terms of interaction between dislocations and point defects, i.e. intrinsic point defects (titanium interstitials) at the largest departures from stoichiometry and extrinsic impurities for compositions close to $\mathrm{TiO}_{2}$.

Regarding to the fact that the temperature of $1323 \mathrm{~K}$ is above half the melting point, the strong hardening effect observed at the flow stress level in the intrinsic regime has to be emphasized for softening effect,accompanied by work-softening at large strains, has been extensively reported in non-stoichiometric oxides at elevated temperatures $/ 14 /$.

Technical improvements of the apparatus are needed to increase the rate of cooling from the reduction temperature for conclusive TEM microstructural observations. These should allow a better understanding of the defect structure at the deformation temperature and of the worksoftening effect observed at large strains. Extension of the range of compositions and temperatures investigated is also necessary to confirm the yielding mechanism. All these studies are presently under way. Acknoẃledgements.- We are very grateful to C. Picard (Laboratoire des Composés Non-Stoechiomëtriques, Université Paris Sud, orsay) who kindly

( $\left.{ }^{1}\right)$ The concentration of the aliovalent impurities in the specimens studied by Baumard /13/ was about 100 p.p.m. 
made the thermogravimetric measurements on our samples. We wish to thank P. Faisant for his help when designing and building the experimental device. Ne are also indebted to G. Fontaine and $\mathrm{C}$. Picard for helpful discussions during this work.

\section{References}

/1/ Blanchin, M.G., Bursil.,L.A., Hutchison, J.L., Gai, P., (1981) this volume

/2/ Picard, C., Gerdanian, P., J. Solid State Chem. 14 (1975) 66

/3/ Blumenthal, R.N., Whitmore, D.H., J. Electrochem. Soc. $110(1963) 92$

/4/ Zador, S., Electromotive force measurements in high temperature systems, (Institute of Mining and Metaliurgy, London) 1968 , p. 145

15/ Baumard, J.F., Panis, D., Anthony, A.M., J. Solid state Chem. 20 (1977) 43

/6/ Blanchin; M.G., Faisant, P., Picard, C., Ezzo, M., Fontaine, G., Phys. Status Solidi (a) 60 (1980) 357

17/ Vrinat, M., Thèse Docteur-Ingénieur (1980) Lyon

/8/ Blanchin, M.G., Faisant, P., Revue Phys. Appl. 14 (1979) 619

19/ Blanchin, M.G., Fontaine, G., Kubin, L.P., Phịlos.Mag. $41 \quad(1980) 261$

/10/ Groh, P., Dislocations et Déformation plastique (Editions de Physique, Paris) 1980,p. 71

111/ Guyot, P., Dislocations et Déformation plastique (Editions de Physique, Paris) 1980,p. 193

/12/ Odier, P., Baumard, J.F., Panis, D., Anthony, A.M., J. Solid State Chem. 12 (1975) 324

/13/ Baumard, J.F., Thèse Doctorat ès Sciences (1977) Orléans

/14/ Blanchin, M.G., Castaing, J., Fontaịne, G., Heuer, A.H., Hobbs, L.W., Mitchell, T.E., (1981) this volume 